\title{
Diagnostic Performance of Three Serological Assays for Anti-SARS-CoV-2 Antibody Detection
}

\author{
Shabnam Dildar ${ }^{1}$, Asma Danish², Mehjabeen Imam ${ }^{1}$, Arshi Naz ${ }^{1}$, Tahir Sultan Shamsi ${ }^{2, *}$ \\ ${ }^{1}$ Department of Pathology, National Institute of Blood Disease \& Bone Marrow Transplantation, Karachi, Pakistan. \\ ${ }^{2}$ Department of Hematology, National Institute of Blood Disease \& Bone Marrow Transplantation, Karachi, Pakistan.
}

\begin{abstract}
Objective: To evaluate the diagnostic performance of Electrochemiluminescence (ECLIA) enzyme linked immunosorbent (ELISA) and lateral flow Immunofluorescence (LFIA) for anti-SARS-COV-2 antibody detection.

Materials and Methods: Sensitivity was calculated with convalescent plasma (CP) donor's samples. Specificity was checked by using pre-pandemic October 2019 samples. All samples were tested for anti-SARS-COV-2 antibody by using Electrochemiluminescence (ECLIA), Enzyme Linked Immunosorbent Assay (ELISA) and Lateral flow Immunofluorescence (LFIA) assay.
\end{abstract}

Results: Total 55 patients were included, 45 patients were CP donors and 10 were Pre-Pandemic October 2019 samples archived from our blood bank. The ECLIA-total antibody, ELISA-IgG and LLFIA-IgG were positive in 41 (91.1\%), 34 (75.5\%) and 44 (97.75\%) respectively. The highest sensitivity was observed for LFIA with highest specificity among all three assays. There was almost perfect agreement between LFIA and ECLIA $(\mathrm{k}=0.936, \mathrm{p}<0.001)$ but there was fair agreement between LFIA and ELISA $(\mathrm{k}=0.412, \mathrm{p}=0.001)$ and ECLIA and ELISA $(\mathrm{k}=0.357, \mathrm{p}=0.001)$.

Conclusion: The LFIA showed a higher sensitivity and specificity in comparison with ECLIA and ELISA. It might be due to fact that LFIA detect antibody against ncleocapsid and spike protein as well of SARS- COV-2 virus, while ECLIA and ELISA detects antibodies only against "N" Protein of SARS- COV-2 virus.

Keywords: Convalescent plasma donors, Lateral flow Immunofluorescence assay, Electrochemiluminescence assay, Enzyme linked immunosorbent assay, Performance.

\section{INTRODUCTION}

In December 2019, an outbreak of pneumonia and upper respiratory infection caused by SARS-COV-2 virus started in China, then spreading globally to finally being stated as a Pandemic by WHO on March 11, 2020 [1].

Although diagnosis of RNA of corona virus by Reverse transcription polymerase chain reaction (RT-PCR) in respiratory tract secretions has become "Gold Standard Test" for diagnosis of COVID-19 disease [2]. RT-PCR has some limitation. The degradation of purified RNA, RT-PCR inhibitors, and genomic mutations can lead to false-negative results [3-5]. Erroneous results may occur due to inadequate sample collection, storage, transport, purification, processing quality of the RNA. False-positive results may occur due to cross-contamination of samples during collection, pipetting, processing and other technical faults [6]. After availability of COVID-19 Antigen Rapid Diagnostic Test (Ag-RDT) for diagnosis; many countries across the world have incorporated COVID-19-Ag-RDT test in their testing strategies for disease mapping purposes [2].

Clinicians worldwide are focusing on serological testing of COVID-19 to assess prior infection, exposure, immune status,

*Address correspondence to this author at the Department of Hematology, National Institute of Blood Disease \& Bone Marrow Transplantation,

Karachi, Pakistan. Email: t.shamsi.62@gmail.com epidemiologic survey, serosurveillance, vaccine development and also for identification of convalescent plasma (CP) donors $[7,8]$.

The serologically significant proteins of SARS-CoV-2 virus are spike and nucleocapsid protein, involved in transcription, replication, and incorporation into host's cell cycle and are highly immunogenic $[7,8]$. Keeping in view the speed of COVID-19 spread, point of care testing is now being explored. Many studies are done on ELISA, ECLIA and LFIA for anti-SARS-COV-2 antibody detection, but mostly done on IgG and IgM antibodies only few done on total antibodies [9, 10]. These serological tests need further validation for accurate and reliable results. Our objective was to determine diagnostic performance of Electrochemiluminescence (ECLIA) Enzyme Linked Immunosorbent (ELISA) and lateral flow Immunofluorescence (LFIA) for anti-SARS-COV-2 antibody detection.

\section{MATERIALS AND METHODS}

This prospective study was done at National Institute of Blood Disease \& Bone Marrow Transplantation (NIBD) at Karachi, Pakistan from 15th May 2020 to 20th August 2020. Ethical approval of study was taken from Institutional Review board (IRB). Adult corona survivors (earlier diagnosed with 
COVID-19 with positive RT-PCR) male of female with aged 18 to 60 years, with no co-morbidities, fully recovered from COVID-19 were with RT-PCR negative involved in the study. Blood sample was taken 14 days after the date of symptoms onset of all subjects. Three to five $\mathrm{ml}$ blood was collected for serological testing. The anti-SARS-CoV-2-IgG was analyzed by using IgG-ELISA and IgG-LFIA method, while total antibody (IgG,IgM and $\operatorname{IgA}$ ) by using ECLIA assay.

\section{Lateral Flow Immunofluorescence Assay (LFIA)}

This assay detects anti-SARS-CoV-2 IgG qualitatively by Indirect Immunofluorescence Chromatography on FA series lateral flow Immunoassay analyzer. SARS-Co-V assay kit provided by Shenzhen Lifotronic Technology Co,Ltd Shenzhen, China. This assay uses recombinant antigens against Nucleocapsid (N) and Spike (S) protein of SARS- CoV-2 virus. Cut off of more than equal to $5 \mathrm{U} / \mathrm{mL}$ was used to label as positive as and less than $5 \mathrm{U} / \mathrm{mL}$ was used to label negative $[11,12]$.

\section{Enzyme Linked Immunosorbent Assay (ELISA)}

This assay detects Covid antibody against Nucleocapsid protein of SARS-CoV-2 virus. We used qualitative kit of anti-SARS-CoV-2-IgG Kit by Generic Assays (GA), Dehlewitz, Germany cut off of more than equal to $1.1 \mathrm{U} / \mathrm{mL}$ was used to label as positive as and less than $1.1 \mathrm{U} / \mathrm{mL}$ was used to label negative.

\section{Electro-Chemiluminescence Immunoassay (ECLIA)}

This assay detects anti-SARS-CoV-2 total antibody (IgG, IgM, and IgA) by using Roche Cobas e-411 Immunoassay analyzer. It detects antibodies against $\mathrm{N}$ proteins. Cut of Index (COI) of more than 1.0 was use to label as Reactive, COI of less than 1.0 use to labeled as Non-Reactive as per manufacturer recommendation.

\section{DATA ANALYSIS}

Descriptive statistics such as frequency percentages, mean and standard deviation were calculated. Diagnostic accuracy including sensitivity, specificity, positive predictive value (PPV) and negative predictive value (NPV) was calculated. Cohen's Kappa was run to determine the agreement among IgG-LFIA, ECLIA-total antibody and IgG-ELISA. Cohen kappa value of $<0$ labeled as no agreement, $0.01-0.20$ labeled as slight agreement, $0.21-0.40$ fair agreement, $0.41-0.60$ moderate agreement, $0.61-0.80$ substantial agreement, and 0.81-0.99 labeled as perfect agreement [13]. All analysis was done on SPSS version 23.

\section{RESULTS}

Fifty five patient samples were involved and majority were $(84.4 \%)$ males, forty five were convalescent plasma (CP) donor's samples and ten were pre-pandemic October 2019 samples archived from blood bank department. Sensitivity was calculated from $\mathrm{CP}$ donor samples while specificity was checked by using Pre-Pandemic October 2019 samples. The mean age of patients was $34 \pm 13.6$ years. ECLIA-total antibody, ELISA-IgG and LFIA-IgG were positive in 41 $(91.1 \%), 34(75.5 \%)$ and $44(97.75 \%)$ respectively. The highest sensitivity was observed for LFIA (Table 1) with highest specificity among all three assays.

There was almost perfect agreement between LFIA and ECLIA $(\mathrm{k}=0.936, \mathrm{p}<0.001)$ but there was fair agreement between LFIA and ELISA $(\mathrm{k}=0.412, \mathrm{p}=0.001)$ and ECLIA and ELISA $(\mathrm{k}=0.357, \mathrm{p}=0.001)$ (Table 2).

Table 1. Performance of Three Serological Assays.

\begin{tabular}{|l|c|l|l|}
\hline $\begin{array}{c}\text { Diagnostic Accuracy } \\
\text { Parameters }\end{array}$ & $\begin{array}{c}\text { ECLIA (Total } \\
\text { Antibody) }\end{array}$ & $\begin{array}{c}\text { IgG- } \\
\text { ELISA }\end{array}$ & $\begin{array}{c}\text { IgG- } \\
\text { LFIA }\end{array}$ \\
\hline Sensitivity (\%) & 91.1 & 75.6 & 97.7 \\
\hline Specificity (\%) & 80.0 & 80.0 & 90.1 \\
\hline $\begin{array}{l}\text { Positive Predictive } \\
\text { Value (\%) }\end{array}$ & 95.3 & 94.4 & 97.8 \\
\hline $\begin{array}{l}\text { Negative Predictive } \\
\text { Value (\%) }\end{array}$ & 66.7 & 42.1 & 90.0 \\
\hline
\end{tabular}

Table 2. Agreement of Three Serological Assays.

\begin{tabular}{|l|c|c|c|}
\hline Serological Assays & $\begin{array}{c}\text { Kappa } \\
\text { Statistics }\end{array}$ & Agreement & p-value \\
\hline LFIA and ECLIA & 0.936 & Perfect agreement & $<0.001$ \\
\hline LFIA and ELISA & 0.412 & Fair agreement & 0.001 \\
\hline ECLIA and ELISA & 0.357 & Fair agreement & 0.003 \\
\hline
\end{tabular}

\section{DISCUSSION}

Center of Disease Control and Prevention (CDC) recommends RT-PCR as a preferred diagnostic test for COVID-19, however serological tests have emerged with a high rate of sensitivity. A Randomized controlled trial showed that use of high-titer convalescent plasma against SARS-CoV-2 virus within 72 hours after the onset of mild to moderate symptoms can decrease the progression of Covid-19 disease [13-15]. These patient derived antibodies are capable to neutralize the SARS-CoV-2 virus [16].

In Present study we assessed the performance of LFIA, ECLIA and ELISA assay; we checked anti-SARS-COV-2 14 days after the symptoms onset in CP donors who recovered from COVID-19 infection. ECLIA total antibody assay had sensitivity of $91.1 \%$ and specificity of $80 \%$, IgG-LFIA assay had sensitivity of $97.7 \%$ and specificity of $90.1 \%$, its perfor- 
mance was good as compared to ECLIA total antibody and IgG-ELISA assay.

Jhong Lin $\mathrm{Wu}$ et al. evaluated anti- SARS-COV-2 IgG/IgM antibody response checked on four point-of-care (POC) rapid devices and check seroconversion checked 3 weeks after the symptom onset; they found overall sensitivity and specificity of $100 \%$ and $100 \%$ respectively and no significant difference was seen in separate rapid device used of $\operatorname{IgM}$ and $\operatorname{IgG}$ with those combined total antibody (mainly IgM/IgG) determination [17].

Elslande et al. evaluated seven LFIA-IgG/IgM and ELISA-IgG rapid devices, he checked 2-4 weeks after symptoms onset and found sensitivity of $92.1 \%$ and $89.5 \%$ respectively [18]. Another review conducted by Bastos et al. they determined the diagnostic accuracy of serological tests and they found the cumulative sensitivity of ELISA-IgG and IgM was $84.3 \%$ of LFIAs was $66.0 \%$, and of ECLIAs were $97.8 \%$. The pooled specificities ranged from $96.6 \%-99.7 \%$ [19, 20].

We included small number of subjects and compare two IgG assays with one total antibody (IgG,IgM and $\operatorname{IgA}$ ) assay, but this total assay have high affinity for IgG, The strength of the study was that we compared three serological assays.

\section{CONCLUSION}

The LFIA showed a higher sensitivity and specificity in comparison with ECLIA and ELISA. It might be due to fact that LFIA detect antibody against "N" and "S" protein as well of SARS- COV-2 virus, while ECLIA and ELISA detects antibodies only against "N" protein of SARS- COV-2 virus.

\section{FUNDING}

Self-funded

Availability of Data and Material

Data will provide upon the request, keeping in mind the confidentiality of patients.

\section{AUTHORS' CONTRIBUTION}

Shabnam Dildar: Designed the study, analyze data, wrote the manuscript.

Asma Danish: Wrote manuscript.

Mehjabeen Inam: Review manuscript.

Arshi Naz: Review manuscript.

Tahir Sultan Shamsi: Review manuscript.

\section{CONFLICT OF INTEREST}

Declared none.

\section{ACKNOWLEDGEMENTS}

Declared none.

\section{REFERENCES}

[1] Cucinotta D, Vanelli M. WHO declares COVID-19 a pandemic. Acta Biomed 2020; 91(1): 157-60.

[2] Government of Pakistan. Guidelines testing strategy incorporating covid-19 antigen detection rapid diagnostic tests (Ag-RD T), ministry of national health services, regulation and coordination. 2020; Document code: 53-01: version: 01. Available at: https://covid.gov.pk/

[3] Chen N, Zhou M, Dong X, et al. Epidemiological and clinical characteristics of 99 cases of 2019 novel corona virus pneumonia in Wuhan, China: A descriptive study. Lancet Lond Engl 2020; 395: 507-13. DOI: 10.1016/S0140-6736(20)30211-7

[4] Huang C, Wang Y, Li X, et al. Clinical features of patients infected with 2019 novel corona virus in Wuhan, China. Lancet Lond Engl 2020; 395: 497-506.

DOI: 10.1016/S0140-6736(20)30183-5

[5] Liu R, Han H, Liu F, et al. Positive rate of RT-PCR detection of SARS-CoV-2 infection in 4880 cases from one hospital in Wuhan, China, from Jan to Feb 2020. Clin Chim Acta 2020; 505: 172-5. DOI: $10.1016 /$ j.cca.2020.03.009

[6] Afzal A. Molecular diagnostic technologies for COVID-19: Limitations and challenges J Adv Res 2020; 26: 149-59. DOI: $10.1016 /$ j.jare.2020.08.002

[7] Theel ES, Slev P, Wheeler S, et al. The Role of antibody testing for SARS-CoV-2: Is there one? J Clin Microbiol 2020; 58(8): e00797-20. DOI: 10.1128/JCM.00797-20

[8] Abraham Peele K, Srihansa T, Krupanidhi S, Ayyagari VS, Venkateswarulu TC. Design of multi-epitope vaccine candidate against SARS-CoV-2: A in-silico study. J Biomol Struct Dyn 2020; 1-9. DOI: 10.1080/07391102.2020.1770127

[9] Du Z, Zhu F, Guo F, et al. Detection of antibodies against SARS-CoV-2 in patients with COVID-19. J Med Virol 2020; 92(10): 1735-8. DOI: $10.1002 / \mathrm{jmv} .25820$

[10] Li Z, Yi Y, Lou X, et al. Development and clinical application of a rapid IgM-IgG combined antibody test for SARS-CoV-2 infection diagnosis. J Med Viral 2020; 92(9): 1518-24.

DOI: $10.1002 /$ jmv. 25727

[11] Lu R, Zhao X, Li J, et al. Genomic characterization and epidemiology of 2019 novel corona virus: Implications for virus origins and receptor binding. Lancet 2020; 395(10224): 565-74. DOI: 10.1016/S0140-6736(20)30251-8

[12] SARS-CoV-2 Antigen \& Antibody Detection Kit. User manual. China: Lifotronic Technology Co., Ltd. 2021. Available at: https://healthcare-in-europe.com/en/labbook/foc $\mathrm{u} \quad \mathrm{s} \quad-\quad \mathrm{o} \quad \mathrm{n} \quad-\quad \mathrm{c}$ h $\mathrm{i}$ na/2425-lifotronic-sars-cov-2-antigen-antibody-detection-kit. html 
[13] Viera AJ, Garrett JM. Understanding interobserver agreement: The kappa statistic. Fam Med 2005; 37(5): 360-3.

[14] Ahn JY, Sohn Y, Lee SH, et al. Use of convalescent plasma therapy in two COVID-19 patients with acute respiratory distress syndrome in Korea. J Korean Med Sci 2020; 35(14): e149. DOI: $10.3346 / j \mathrm{kms} .2020 .35 . \mathrm{e} 149$

[15] Luetkens T, Metcalf R, Planelles V, et al. Successful transfer of anti-SARS-CoV-2 immunity using convalescent plasma in an MM patient with hypogammaglobulinemia and COVID-19. Blood Adv 2020; 4(19): 4864-8.

DOI: $10.1182 /$ bloodadvances. 2020002595

[16] Libster R, Pérez Marc G, Wappner D, et al. Early high-titer plasma therapy to prevent severe COVID-19 in older adults. N Engl J Med 2021; 384: 610-18.

DOI: $10.1056 /$ NEJMoa2033700

[17] Wu J-L, Tseng W-P, Lin C-H, et al. Four point-of-care lateral flow immunoassays for diagnosis of COVID-19 and for assessing dynamics of antibody responses to SARS-CoV-2. J Infect 2020; 81(3): 435-42. DOI: 10.1016/j.jinf.2020.06.023

[18] Van Elslande J, Houben E, Depypere M, et al. Diagnostic performance of seven rapid $\operatorname{IgG} / \operatorname{IgM}$ antibody tests and the Euroimmun IgA/IgG ELISA in COVID-19 patients. Clin Microbiol Infect 2020; 26(8): 1082-7.

DOI: $10.1016 /$ j.cmi.2020.05.023

[19] Lisboa Bastos M, Tavaziva G, Abidi SK, et al. Diagnostic accuracy of serological tests for covid-19: Systematic review and meta-analysis. BMJ 2020; 370: m2516. DOI: 10.1136/bmj.m2516

[20] Asselah T, Lee SS, Yao BB, et al. Efficacy and safety of glecaprevir/pibrentasvir in patients with chronic hepatitis $\mathrm{C}$ virus genotype 5 or 6 infection (ENDURANCE-5, 6): An open-label, multicentre, phase $3 \mathrm{~b}$ trial. Lancet Gastroenterol Hepatol 2019; 4(1): 45-51.

DOI: $10.1016 / \mathrm{S} 2468-1253(18) 30341-8$ 